\title{
Conservando nuestro pasado: Ios sitios arqueológicos del municipio de Ciudad Sandino. Una experiencia de rescate
}

Frances Shellybhet Vanegas Aburto

\begin{abstract}
Resumen
El presente trabajo tiene como propósito general la de crear conciencia entre los pobladores del municipio de Ciudad Sandino, acerca de la importancia de los sitios arqueológicos como patrimonio cultural. La cabecera del municipio de Cuidad Sandino está sobre un asentamiento indígena, cuyos artefactos encontrados, son poco conocido por la población. A esta situación de desinterés, se le agrega, el pillaje y la depredación de los objetos encontrados, poniendo en peligro el valioso patrimonio encontrado. Las autoridades municipales y nacionales, están haciendo todo lo que está a su alcance para el rescate y conservación de las piezas encontradas, creando un museo y generando otras políticas públicas para que la población se apropie de esta iniciativa cultural. La labor de las instituciones, y el comportamiento de la población, forman parte del estudio que se presenta. Otro elemento del trabajo es la vinculación de los sitios arqueológicos con la construcción de la identidad de nicaragüense.
\end{abstract}

Palabras claves: Sitios arqueológicos, asentamiento indígena, historia oral, identidad.

\begin{abstract}
General Porpouse of this work is to créate awareness among people of Ciudad Sandino Municipality, about the importance of archaeological sites and cultural heritage. Ciudad Sandio is located on indigenous settlement, whose devises found are not widely known by inhabitants. This can be due to indifference, but also it occurred robbery predation of found items, which is a risk to archaeological heritage. Local and national authorities are making every effort for rescue and conservation of the pieces found. As a result exist a Museum, and work is doing to generate public policy so that inhabitants appropriates this cultural initiative. Work done by institutions and population response are part of this study. Another topic treated in this work is the relation between archaeological sites and nicarguan identity building.
\end{abstract}

Keywords: archaeological sites, indigenous settlement, oral history, identity.

\section{Introducción}

El presente ensayo hace referencia a la experiencia de conservación de la cultura por medio del rescate de los sitios arqueológicos encontrados en el municipio de Ciudad Sandino. La finalidad es contribuir al fortalecimiento de las identidades, sabiendo que la comprensión del pasado permite responder a preguntas que la humanidad se ha hecho durante toda su existencia: quienes somos como personas, creencias, valores, tradiciones.

Por otro lado, los hallazgos permiten comprender los imaginarios colectivos de esos grupos sociales, y las diferencias existenten entre ellos y otro grupos con los que compartían o mantenían relaciones de conflicto. 
En el trabajo se aborda los orígenes del espacio en estudio, el nacimiento del municipio, destacando algunos de los sitios arqueológicos que se encuentran en el sector de Oro verde. De igual forma se describe el 1 rescate y resguardo de las piezas arqueológicas. Otros aspectos que se describen es lo relacionado a la organización del museo.

Un aspecto que también se menciona en el ensayo es la ayuda por las autoridades municipales al proyecto del museo y la acogida de la población al hallazgo de tan importante tesoro arqueológico en medio de sus hogares brindada al museo por parte de la alcaldía, el impacto de la población al encontrar o descubrir una pieza arqueológica en sus hogares.

Como objetivo central el ensayo busca la concientización de los habitantes del municipio de Ciudad Sandino acerca de la importancia de los sitios o vestigios arqueológicos. La idea de este trabajo surge dentro de las actividades de la asignatura Investigación Histórica III y asignaturas como Introducción a la Arqueología, Museología y Gestión de Patrimonio las cuales sirvieron para el abordaje y/o comprensión lo que es un vestigio arqueológico y la importancia de este para entender las representaciones de sociedades pasadas. La asignatura de museología permitió apropiarse de elementos que contempla una obra museológica, así como entender el concepto de patrimonio y todo lo que ello encierra.

Como estudiante de Historia tuve la oportunidad de trabajar en una excavación arqueológica en el municipio de Ciudad Sandino, gracias a Flor Hernández concejal del municipio. Esta funcionaria me informó del hallazgo de vestigios arqueológicos. $\mathrm{Mi}$ compromiso con el rescate de este patrimonio fue inmediato, incorporándome al equipo de arqueólogos contratados para las tareas de excavación.
Lo anterior explica las razones para desarrollar iniciativas de rescate cultural y del patrimonio. De manera particular, la necesidad de hacer conciencia en la población de la importancia del hallazgo como fuente de información y de promoción turística, lo cual contribuiría al desarrollo del municipio.

El patrimonio cultural encontrado hace referencia a la herencia de los antepasados, tanto los elementos tangibles(los objetos materiales) como intangibles (el imaginario individual o colectivo) heredadas de generación en generación. La importancia o valor que estos elementos es de carácter histórico, arqueológico o paleontológico.

Los sitios arqueológicos o yacimientos, como se le podría llamar son una fuente o concentración de diversos materiales arqueológicos, sea estructura, restos de huesos o medioambientales, etc. Uno de estos materiales es la obsidiana, un material de roca volcánica que era utilizada como ornamento. Para los indígenas, este material era importante, puesto que les ayudaba a fabricar distintos materiales para su sobrevivencia.

Los vestigios arqueológicos son restos de materiales arqueológicos que pueden encontrarse en determinados puntos del país. Los entierros primarios son los esqueletos que están directamente en el suelo; los entierros secundarios son donde se encuentran esqueletos dentro de una urna.

En relación al museo recién creado, es una institución sin fines de lucro, que brinda un servicio a la sociedad. Se ocupa de preservar, resguardar, investigar, exhibir los diversos instrumentos o artefactos encontrados para la educación del público. 


\section{¿Cómo nace Ciudad Sandino?}

En el año 1969, cuando los barrios adyacentes a la costa del lago de Managua, como La Tejera, Miralagos, Quinta Nina, Acahualinca y otros fueron afectados por graves inundaciones debido a la crecida del lago Xolotlán, producidos por una depresión tropical que azotaba la capital. La mayor parte de los damnificados fueron trasladados a un lugar más seguro. El Gobierno de ese entonces, dirigido por Anastasio Somoza Debayle, puso en marcha el proyecto denominado Operación Permanente de Emergencia Nacional (OPEN No. 3). Negoció la compra de las propiedades algodoneras de la familia Blandón, para así asentar a las personas afectadas por la crecida del lago. De esta operación, se crearon las primeras zonas del OPEN-3 (actual núcleo poblacional de Ciudad Sandino) y Bella Cruz, (conocida como Zona No. 8).

80 Según cuentan los entrevistados, primeramente se le dio el nombre de Reparto Santa María, reflejados en los recibos de abonos por la compra de los terrenos y que los Blandón emitían. Posteriormente se le empezó a llamar por el nombre de OPEN3. Los primeros años fueron difíciles, así lo menciona una informante: "se carecía de agua potable, alumbrado público, energía eléctrica, servicios higiénicos, trazado de calles irregulares y del control urbano, en cuanto al desarrollo y ordenamiento del mismo" (Nidia; 2014).

En 1971 no había transporte público, y los pobladores debían caminar hasta el Parque de las Piedrecitas para tomar el bus que llegaba al centro de la ciudad de Managua (la ruta que tomaba el TUN 10 que terminaba en este Parque). El transporte era deficiente, no satisfacía la demanda de los usuarios, por lo que se instaló una cooperativa de buses.

El terremoto que destruyó a Managua en diciembre de 1972, obligó a muchas familias que perdieron sus casas a trasladarse e instalarse en viviendas improvisadas, construidas con ripios o materiales reciclados, en el proyecto OPEN-3. Esta afluencia de familias damnificadas por este desastre contribuyó a al ayudó al crecimiento poblacional del entonces barrio OPEN-3.

El 19 de julio de 1979, se produce el darrocamiento de la dictadura del general Anastasio Somoza Debayle y el ascenso al gobierno del gobierno revolucionario sandinista, Un nuevo escenario político y social nacía con el triunfo de la Revolución popular sandinista, como producto de una larga lucha política y social. .

Una vez que triunfa la revolución y como una reivindicación de uno de los barrios populares, símbolo de la pobreza, la marginación y la lucha por las mejoras sociales, el gobierno revolucionario le cambió el nombre de OPEN-3 por el del héroe revolucionario nicaragüense General Augusto C. Sandino, siendo llamado el barrio a partir de ese momento como Ciudad Sandino. Según se dice, sin que exista una evidencia, que la iniciativa de bautizar con el nombre de héroe se debió al compositor Alberto "El Gato" Aguilar y otros pobladores, al desplegar una manta en lugar con el nombre de Ciudad Sandino, aceptado por la ciudadanía y conservado hasta hoy día.

El Comité Distrital para el desarrollo en el año de 1995, solicitó la aprobación de una Ley que elevara al Distrito al rango de Municipio, argumentando factores geográficos $\mathrm{y}$ socioeconómicos. El proyecto de Ley fue sometido a la Asamblea Nacional. En ese mismo año se produjo el primer hallazgo arqueológico en el municipio mediante una investigación denominada Investigación Metropolitana, dirigido por el arqueólogo Ramiro García. De igual manera, en el año 2006 se encontró otro vestigio arqueológico en Bello Amanecer, y en el año 2010 en Oro Verde. 


\section{Los sitios arqueológicos en Ciudad Sandino}

En sus inicios, el actual territorio que hoy ocupa el municipio de Ciudad Sandino fue un asentamiento precolombino. Nuestros indígenas vieron todas las condiciones ambientales necesarias para satisfacer sus necesidades y habitar estas zonas.

Ahora bien, ¿Cuál es el imaginario colectivo de los pobladores con respecto a los asentamientos indígenas? En la actualidad, se conocen estos asentamientos indígenas, sin embargo la actitud de algunos pobladores es de indiferencia. Al respecto la informante Nidia señala: "La población de este municipio no tenía conocimiento de la importancia de los sitios arqueológicos, por lo menos sus fundadores así lo mencionan" (Nidia, 2014).

El municipio ha sufrido daños ambientales, como producto de las fábricas instaladas en la zona de estos asentamientos indígenas. Esta situación de daño ambiental, dejó al descubierto artefactos y otras piezas arqueológicas. La parte donde más se concentra el asentamiento indígena es en la zona 7, en Oro Verde, porque quedan próximos al lago.

Como se ha señalado, la mayor parte de los habitantes conocen de estos hallazgos, pero tienen una actitud indiferente o de poca conciencia de la importancia de estos materiales. Algunos, cuando encuentran una pieza arqueológica, deciden esconderla o dejarla en su casa para venderla porque existen compradores, sabiendo que con ello se violan leyes de protección del patrimonio nacional. Otras personas han logrado desarrollar cierta conciencia identitaria del significado patrimonio encontrado.

Las personas que valoran como importantes para la cultura de Ciudad Sandino estos hallazgos, llaman de inmediato a las autoridades correspondientes para que hagan el rescate de las piezas en el momento. Ellos respetan el lugar donde las encuentran sin tocarlas, en espera de los especialistas o bien cooperan con los arqueólogos para sacar las piezas.

Dentro de este mismo grupo, se han dado casos de "donaciones" de piezas arqueológicas al museo o Alcaldía del municipio, las cuales han sido incorporados a las colecciones en exposición permanente. De hecho, las piezas entregadas en calidad de donación por algunos pobladores, fueron extraídas en períodos en que no había control o en el pero caso interés de las autoridades nacionales y del municipio sobre este tema.

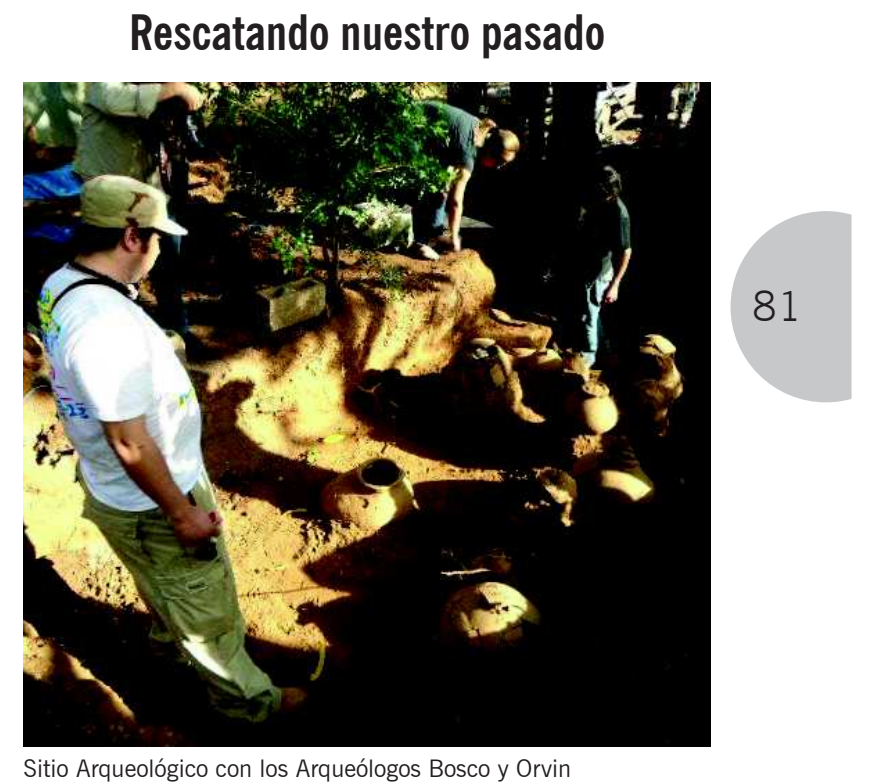

Para mediados del mes de septiembre de 2012, en la zona 7 del Municipio, en el lugar conocido como Oro Verde, un obrero de la construcción que se encontraba realizando trabajos en lugar,encontró una pieza arqueológica, dando parte de manera inmediata a la alcaldía del municipio para que verificaran tal objeto. Las autoridades enviaron al arqueólogo Orvin Zambrana, a la directora del museo, Alicia Urbina, y Bosco Moroney, arqueólogo del Instituto Nicaragüense de Cultura (INC). A este equipo se la estudiante de la carrera de 
Historia, Frances Vanegas Aburto.A partir de esa fecha se inicio el trabajo en este sitio arqueológico, donde se comenzaron trabajos de excavación y encontrando más piezas.

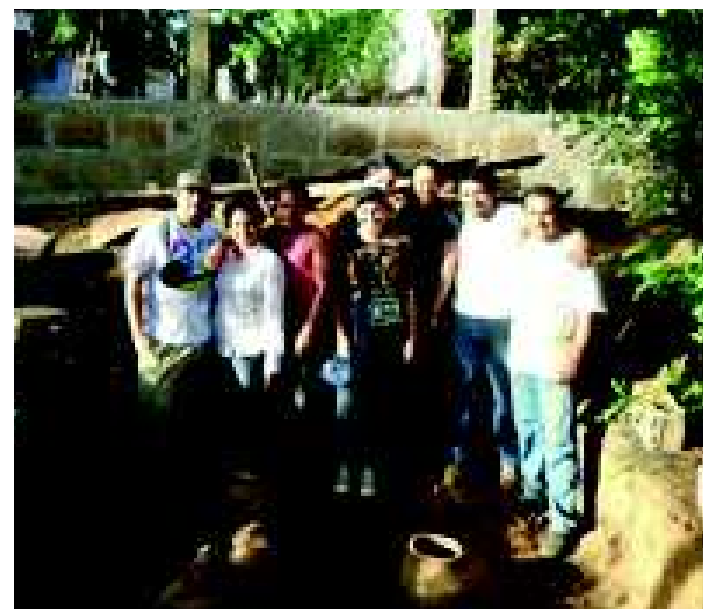

Personas que cooperaron en la excavación del sitio.

Los primeros trabajos fueron prometedores, ya que en la medida en que se excavaba aparecían más objetos. Esta situación hizo que el encargado del equipo, solicitara personal para hacer el rescate de las piezas encontradas. Lo que se encontró fue un cementerio indígena.

Durante esta primera fase de trabajo, se encontraron y rescataron aproximadamente veintinueve piezas arqueológicas, en las cuales había ofrendas con distintos diseños, urnas en forma de zapatos encontrándose en su interior, según el arqueólogo Zambrana:

...dientes, ajuares, semillas, vertebras de pescado, huesos de fauna por lo que podríamos decir que era la principal dieta de los indígenas, esqueletos de niños, piezas dentales ya que las más comunes son de niños, por lo que a veces vamos a encontrar los esqueletos completos, pero la mayoría siempre se encuentran fragmentados por la destrucción del suelo... (Zambrana; 2014)

En el sitio también se encontró obsidiana que era utilizada como ornamento por los indígenas para hacer puntas de flecha, lanzas, entre otros instrumentos. Para el arqueólogo Bosco Maroney del Instituto Nicaragüense de Cultura el hallazgo tiene una “datación del año 800-1550 después de Cristo y es denominado en el periodo cronológico como el periodo Ometepe-Sapoá. (Moroney, 2014). Sin embargo, las ofrendas, a como expresa Zambrana, son del periodo el Mombacho, papagayo, variedad serpiente, del periodo de Ometepe. (Zambrana; 2014). En este descubrimiento se encontró también un entierro primario incompleto. Había el cráneo que estaba a lado del esqueleto, por lo que primeramente se hizo rescate del cráneo y luego del esqueleto.

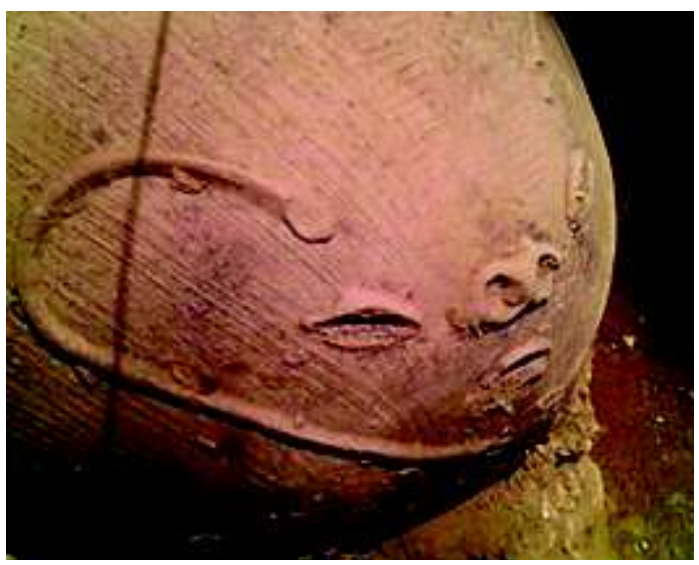

Urna precolombina del periodo ometepe-sapoa

Las piezas fueron llevadas poco a poco al museo del municipio donde se les daría un tratamiento adecuado, análisis, cuido y conservación de las piezas. De igual manera, exhibida en el museo para que la población de Ciudad Sandino apreciara el hallazgo que formaría, desde ese momento, parte del patrimonio del municipio.

En el año 2013 se realizó otro hallazgo arqueológico en un camino cerca de la antigua fábrica de implementos médicos, conocida como PROSAN. En esa ocasión, algunas piezas estaban casi en la superficie. La intervención de los arqueólogos Orvin y Bosco Moroney y la historiadora Frances Vanegas Aburto fue inmediata, rescatando las piezas, y de esa manera evitar mayores daños 


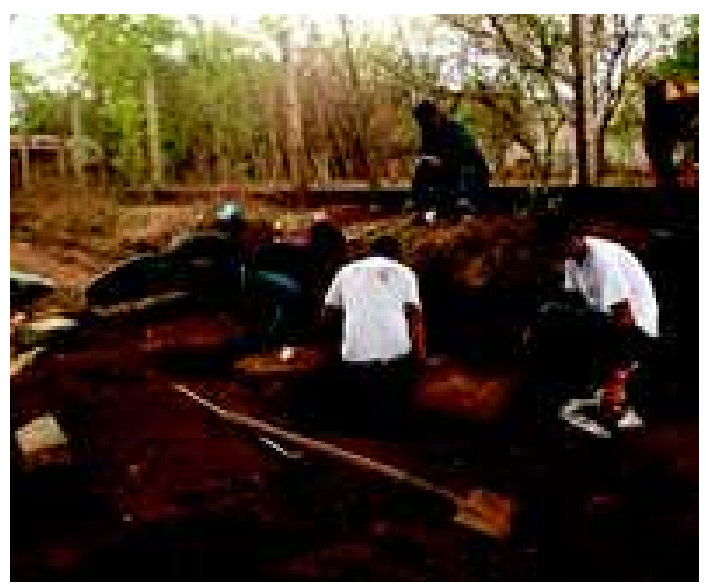

Hallazgo Arqueológico cerca de la fábrica PROSAN. (2013)

$\mathrm{Al}$ ser un camino, los objetos corrían peligro de destruirse por la afluencia de personas y el paso de vehículos. Al final se logró hacer el rescate y las distintas mediciones de las piezas, la profundidad en que estaban y la distancia entre las mismas.

\section{Mano a la obra, capacitación y promoción de cultura}

Primeramente, Ciudad Sandino no contaba con un museo donde se pudieran resguardar las piezas encontradas, por lo que se tenían que resguardar en la alcaldía. Según el informante Urbina:

El museo nace como una iniciativa primeramente del programa educativo Sandino 2, como tesis de fin de año de monografía y fin de curso, se comienza la investigación en el 2010 y finalizando en el 2011 con el montaje del museo de forma empírica y de una forma desorganizada, ya que era un proyectoconlos estudiantes, los cuales no tenían conocimiento de la museología; sin embargo, hicieron el trabajo investigativo. (Urbina; 2014)

Para el año 2012 se instala el museo en la alcaldía. Se comienza el proceso de investigación, a fin de que la población valore la importancia de los hallazgos de piezas arqueológicas. El apoyo de la alcaldía y los hallazgos, hacen que el museo avance en lo que respecta al conocimiento de la población.

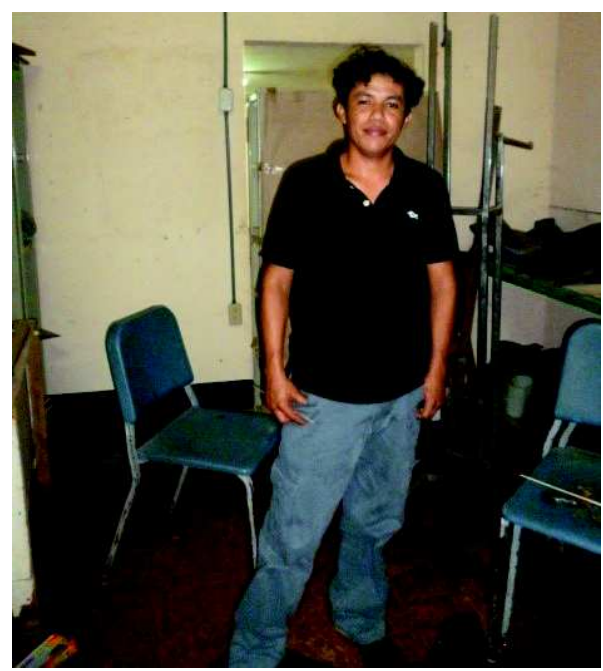

Arqueólogo Orvin Zambrana

Comienza a cultivarse un interés por lo que el museo resguarda. Se preparan programas educativos destinados a la comunidad y de manera particular a los estudiantes. Lo fundamental era darle información de la importancia de los sitios arqueológicos con el fin de que la población se apropiara como suyo este patrimonio. Según un informante:

...proyectos de capacitación en algunos colegios como Augusto C. Sandino, con el colegio Francisco Javier y alegría. Con el colegio Smith, se están haciendo programas para regresar a los orígenes del museo, se capacitaran al Sandino 2, los días domingos. El museo abrirá agenda con esos alumnos nuevos de este programa para que ellos retomen la iniciativa y continúen con esta investigación que no termina aquí, sino que apenas comienza. Con esto, ellos podrán ayudar a promover e investigar más sobre los sitios arqueológicos. (Urbina; 2014).

Como se ha sugerido, una de las iniciativas de las autoridades municipales fue la exhibición de estos artefactos encontrados de culturas pasada asentadas en este territorio, a fin de que los pobladores tuvieran un 
acercamiento a los mismos y le dieran la importancia que tienen para la cultura del lugar. De igual manera, valoraran el esfuerzo de especialistas en la materia que realizan trabajos de conservación del patrimonio del municipio de Ciudad Sandino.

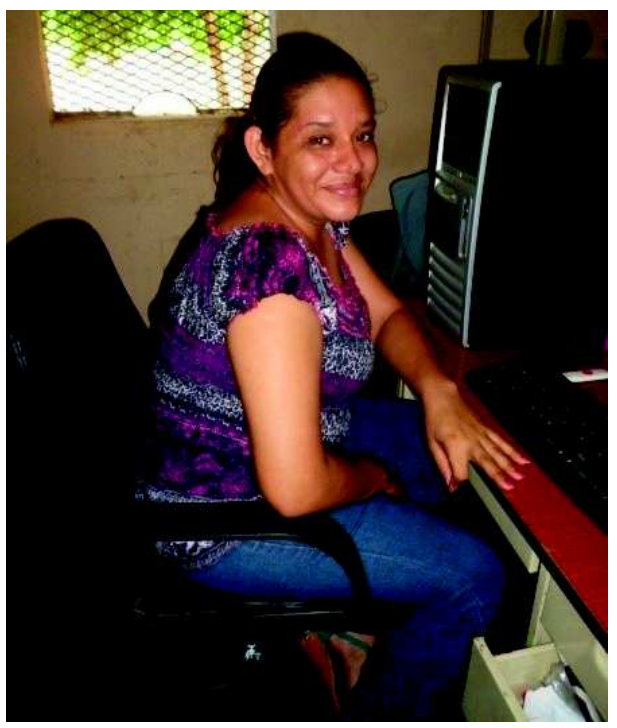

Directora del Museo Alicia Urbina Rodriguez

La Policía, como institución ha sido capacitada por el museo. El propósito es que pueda ayudar al resguardo de aquellos hallazgos de manera expedita, de esa manera se evita posibles destrucciones o vandalismos por parte de pobladores inescrupulosos o de traficantes de piezas arqueológicas.

Ante tales acciones, la Policía aplica la Ley de Protección al Patrimonio Cultural de la Nación, por lo tanto si no respetan la ley los autores de tal delito serán arrestados de seis meses a dos años. Las multas aplicadas van de de 1,000.00 C\$ a C\$.50, 000.00 córdobas. De igual manera, se les decomisa las distintas piezas o instrumentos, las mismas pasan a manos del Instituto de Cultura o bien al museo del municipio, donde las piezas estarán resguardadas y cuidadas por las autoridades correspondientes.

\section{¿De qué forma ayuda la Alcaldía municipal al museo?}

El museo cuenta con un pequeño presupuesto asignado por la alcaldía el cual sirve para la divulgación. En relación a los rescates arqueológicos la alcaldía coopera con los materiales (escobas, palas, brochas y otros instrumentos). También aporta a la alimentación para los arqueólogos o auxiliares.

En ocasiones se recibe ayuda de la vicealcaldesa municipal, quien está a cargo del área de cultura de la alcaldía. Se hacen trabajos en conjunto con el Instituto Nicaragüense de Cultura INC. El museo desempeñó un papel protagónico en la en coordinación, y supervisión técnica, teniendo la colaboración de arqueólogos de la UNANManagua

La reacción de algunos pobladores al encontrarse una pieza arqueológica en su casa, es de sorpresa y agrado. Así lo expresa doña Marta, quien encontró objetos o artefactos en su terreno y de manera responsable se presentó a la alcaldía reportando los hallazgos y cooperando en la recuperación.

Doña Marta también expresa que para ella es importante darse cuenta de que son objetos

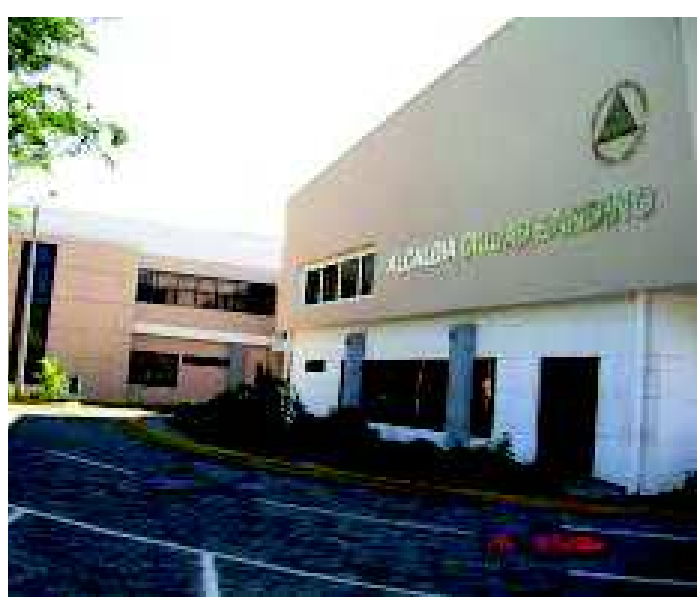

Alcaldía de Ciudad Sandino 
importantes que significan mucho para la población del municipio. Ella misma asegura que no tenía un conocimiento al respecto, $\mathrm{y}$ que por medio de la información que le dio el arqueólogo y la directora del museo se pudo dar cuenta de la importancia de las piezas arqueológicas y del patrimonio de su municipio.

Mientras una parte de la población se siente feliz al encontrar dichos objetos arqueológicos, otros no le dan importancia. Algunos encuentran la pieza, y la ocupan de forma utilitaria o la destruyen. Pero también se encuentran personas conscientes de la importancia de los hallazgos arqueológicos y eso ha contribuido a la conformación de una política municipal que promueve el rescate y conocimiento de las culturas ancestrales asentadas en esta zona del municipio.

Conclusiones

Se sabe que las comunidades indígenas se asentaron en lo que hoy es la zona 7 de Ciudad Sandino, en el lugar de Oro Verde, donde se han encontrado los mayores vestigios arqueológicos. Se puede decir que la geografía y los recursos eran propicios para que nuestros antepasados se asentaran en dicho lugar, el lago, vegetación, entre otros.

Estos hallazgos hacen necesario la conservación y/o preservar del legado de nuestros antepasados, ya que son los pocos recursos que tenemos a disposición para comprenderlassociedadesylacultura deestos antiguos habitantes. Igualmente representan una oportunidad para la configuración de la historia de los antepasados nicaragüenses.

Otro aporte de estos hallazgos está relacionado a la formación de los jóvenes, dado que por medio del museo sirve de apoyo a los estudiantes de secundaria. Para los padres de familia, el tener conocimiento sobre estos sitios les permite sensibilizarse sobre el tema y aportar de manera indirecta a su conservación.

\section{Referencias bibliográficas}

Camarero, M, Morales, T, y Necoechea, G (1994) Rescatando Nuestro pasado: técnicas de historia oral. México D.F.

Benadiba, L. (2007). Historia oral, relatos y memorias. Buenos Aires.

Gutierres, C. A. (2003). Entorno socioeconómico de México. México: México Grabación en audio.

Obando, N, (2014 Septiembre) [entrevista con el señora Nidia, O. Habitantes históricos del Municipio de Ciudad Sandino] Grabación de audio.

Urbina, A, (2014 Septiembre) [entrevista con la señora Alicia, U. Habitante del Municipio de Ciudad Sandino] Grabación de audio.

Zambrana, O, (2014 Septiembre) [entrevista con el señor Orvin, Z. Habitante del Municipio de Ciudad Sandino] Grabación de audio. 
Relación de entrevista grabada

\begin{tabular}{|c|c|c|c|c|c|c|}
\hline $\begin{array}{c}\text { Tipo de } \\
\text { Entrevista }\end{array}$ & Fecha y hora & Lugar & $\begin{array}{c}\text { Nombre del } \\
\text { entrevistado }\end{array}$ & $\begin{array}{c}\text { Criterio de } \\
\text { selección }\end{array}$ & Ocupación & Edad \\
\hline $\begin{array}{c}\text { Grabación de } \\
\text { audio }\end{array}$ & $\begin{array}{c}12 \text { de } \\
\text { Septiembre } \\
\text { de } 2014 \\
2: 45 \mathrm{pm}\end{array}$ & $\begin{array}{c}\text { Museo de } \\
\text { Ciudad } \\
\text { Sandino }\end{array}$ & Alicia Urbina & $\begin{array}{c}\text { Informante } \\
\text { clave. }\end{array}$ & $\begin{array}{c}\text { Directora del } \\
\text { Museo } \\
\text { de Ciudad } \\
\text { Sandino }\end{array}$ & 47 \\
\hline $\begin{array}{c}\text { Grabación de } \\
\text { audio }\end{array}$ & $\begin{array}{c}12 \mathrm{de} \\
\text { Septiembre } \\
\text { de } 2014 \\
3: 15 \mathrm{pm}\end{array}$ & $\begin{array}{c}\text { Museo de } \\
\text { Ciudad } \\
\text { Sandino }\end{array}$ & Orvin Zambrana & $\begin{array}{c}\text { Informante } \\
\text { clave. }\end{array}$ & $\begin{array}{c}\text { Arquélogo } \\
\text { cabecera } \\
\text { de Ciudad } \\
\text { Sandino. }\end{array}$ & 31 \\
\hline $\begin{array}{c}\text { Grabación de } \\
\text { audio }\end{array}$ & $\begin{array}{c}\text { Septiembre } \\
\text { de } 2014 . \\
1: 16 \mathrm{pm}\end{array}$ & $\begin{array}{c}\text { Plaza } \\
\text { de Ciudad } \\
\text { Sandino. }\end{array}$ & Nidia Obando. & $\begin{array}{c}\text { Fundadora } \\
\text { de Ciudad } \\
\text { Sandino. }\end{array}$ & Ama de casa. & 71 \\
\hline
\end{tabular}
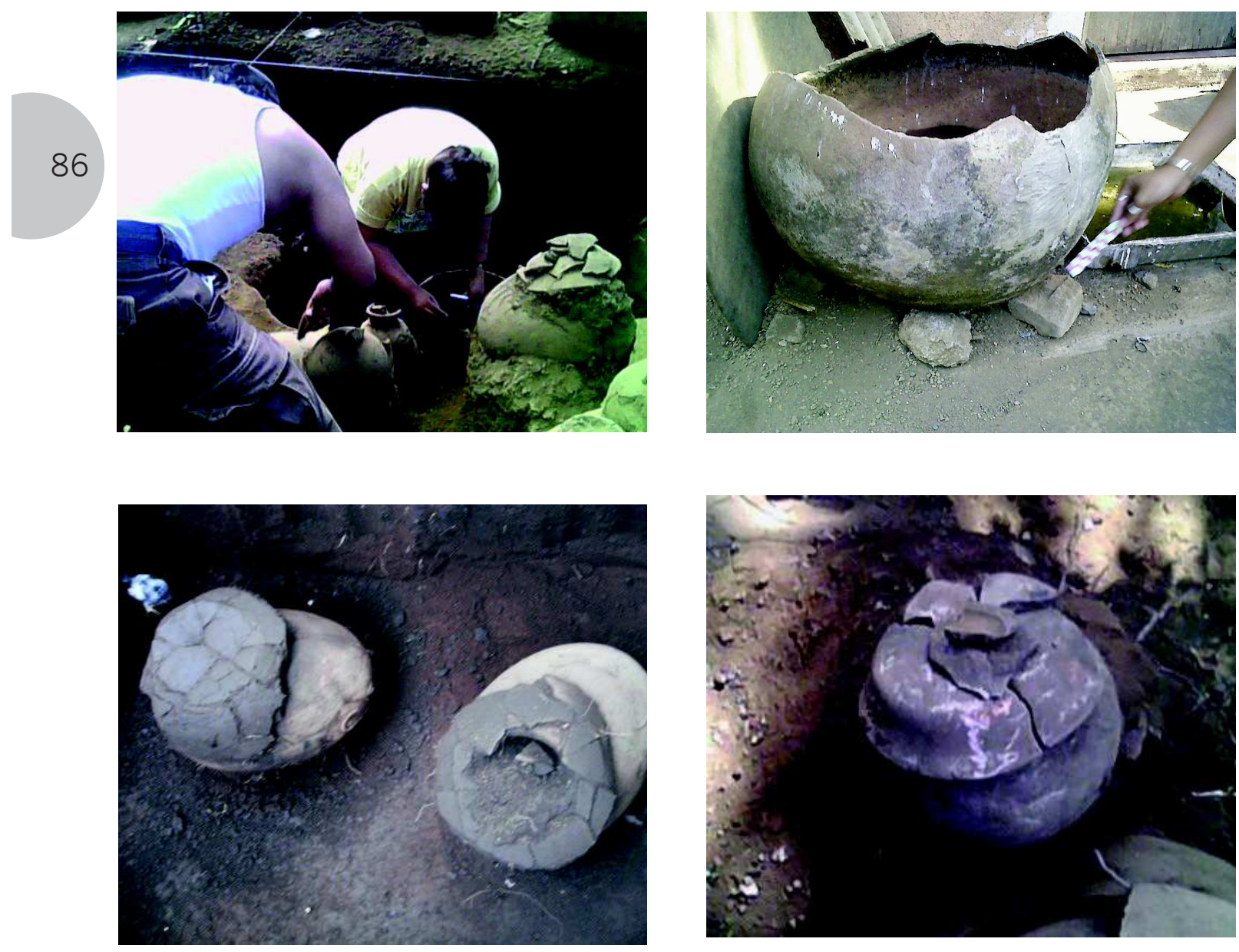